\title{
Peer assessment in health professions education
}

\author{
Wiam Elshami ${ }^{1,}$, , Mohamed Elhassan Abdalla ${ }^{2}$ \\ ${ }^{1,2}$ Assistant Professor, ${ }^{1}$ Dept. of Medical Diagnostic Imaging, College of Health Sciences, University of Sharjah, United Arab \\ Emirates, ${ }^{2}$ Medical Education Unit, College of Medicine, University of Sharjah, United Arab Emirates
}

Corresponding Author:

Email: melsayed@sharjah.ac.ae

\begin{abstract}
Objectives: The aim of this review is to appraise the available literature on peer assessment, its implementation, students' perceptions and its strengths and limitations.

Materials and Methods: A search was prospectively designed to locate the literature relevant to achieving the aims of the review. A pilot review was conducted to ascertain the volume of literature. A wide range of closely related search terms was utilised and combined.

Results: Results of the review show that peer assessment is a valuable experience, and most students enjoy the peer assessment process. The mutual process of peer assessment has a positive impact on students' learning; it allows students to evaluate themselves, comment on each other's work and develop more detailed knowledge. It motivates them to achieve better learning outcomes, promotes self-awareness and increases confidence. Students' involvement in the assessment process supports their learning and encourages reflection. Peer assessment improves clinical performance, as it develops critical thinking and problemsolving skills, encourages self-assessment and promotes reflective practice.

Conclusions: Similar to all assessment methods, peer assessment has advantages and drawbacks. Concerns about the reliability and validity of peer assessment are raised in the literature. To overcome these drawbacks, authors recommend double marking by faculty members, multiple peer assessors, and clear grading criteria. Furthermore, providing written feedback rather than grades, as well as ensuring anonymity, are recommended in the peer assessment process to ensure a safe environment that can promote students' comfort. Nevertheless, student support throughout the peer assessment process is important for proper implementation.
\end{abstract}

Keywords: Peer assessment, Peer assessment implementation, Assessment in health professions education.

\section{Introduction}

The purpose of curricula is to ensure that students study and learn well. ${ }^{1}$ Evaluations of learning and its quality are functions of the assessment process, which involves collecting and evaluating information to measure students' progress. ${ }^{2,3}$ Assessment is considered a pivotal element of the curriculum, and it directs and influences learning. Moreover, assessment motivates students and promotes the higher order of thinking skills through testing, measuring and providing feedback. ${ }^{3-10}$

A student's learning is influenced by the student's perception of assessment. ${ }^{11}$ Thus, depending on the type of assessment being used, a student can adopt a surface learning approach, learn unconnected facts, and memorise the subject matter; this approach may be used when the focus of the assessment is based on the recall of knowledge ${ }^{12}$ or is irrelevant to the student beyond passing the exam. ${ }^{13}$ In contrast, a student can adopt a deep learning approach and make sense of, think and integrate concepts $^{10}$ when the assessment addresses higher cognitive functions and is effectively related to the curriculum's objectives. ${ }^{3}$ Nevertheless, other contextual factors can affect a student's approach to learning, such as the student's workload, the curriculum design and the teaching methods used. ${ }^{14}$

Assessment can be either summative and/or formative. Formative assessment refers to the evaluation process used by faculty or students to measure a student's understanding of the material and guide the student's learning during the study period. ${ }^{15-18}$ It is reported that higher achievement on final assessments may be due to students' participation in formative assessment. ${ }^{15,19,20}$ Summative assessment is used at the end of the study period to evaluate students' learning and assess their academic achievement; it is important for institutional accountability, graduation, and certification. ${ }^{21}$ Both summative assessment and grading direct students away from their need to improve and lead them to collect marks, with the goal of achieving high grades. ${ }^{12}$ However, the summative assessment may be combined with feedback for better results. ${ }^{22}$ Therefore, combining both summative and formative assessments is better for the achievement of curriculum objectives. ${ }^{23}$ Although teachers usually assess their students, it is also recognized that students can assess each other as peers. The aim of this review is to appraise the available literature on peer assessment, its implementation, students' perceptions of it, and its strengths and limitations.

\section{Materials and Methods}

A search was prospectively designed to locate the literature relevant to achieving the aims of the review. A pilot review was conducted to ascertain the volume of literature. During these pilots, we found literature in which peer assessment is classified under formative assessment. For example, Norcini et al. and Cox et al. describe peer assessment as part of the formative 
assessment that affects students' learning experiences by reinforcing their intrinsic motivation to learn and inspiring them to set higher standards for themselves. ${ }^{6,7}$ Therefore, we decided to use "peer assessment" and "formative" or "learning experience" as keywords for the literature search.

Selected papers were required to meet the following inclusion criteria: 1) be written in the English language, 2) contain peer assessment, 3) focus on learning outcomes 4) and include healthcare students as study subjects.

An online search engine (Summon) was used to review the existing literature. Summon has access to multiple databases such as ProQuest, EBSCO HOST, Wiley Online Library, Science Direct and Emerald.

A wide range of closely related search terms was utilised and combined in our search design. The use of similar search terms (e.g., 'peer' vs. 'peer-') was helpful in identifying relevant literature. Search terms were as follows: 1) assessment; 2) peer, peer-, peers; 3) student(s), medical student(s), nursing student(s); 5) teacher, teachers, faculty, faculties; 4) educate(s), education; 5) formative; 6) learning experience. This search was performed in October 2014. Titles and abstracts - screened with relevant studies - were read to determine eligibility. Citations of selected articles were also screened for the purpose of augmenting our search results.

\section{Results}

The search revealed a large amount of literature (2,021 resources). Consequently, magazine articles, trade publications, newsletters and newspaper articles were excluded. After the removal of duplicates, the remaining literature was skimmed, and many items concerned with peer review of work skills in professional employment, academic writing, and professional facilities unrelated to higher education were excluded from the review. All items unequivocally focusing on peer assessment between students in higher education were selected for inclusion. However, additional search terms were identified during the literature reviews, such as assessment for learning. Therefore, some studies were included in the review because they provided essential discussions of the objectives.

Data analysis was conducted using simple descriptive analysis, and frequently recurring topics were categorized, resulting in the emergence of different themes. These themes mainly pertained to the definitions, theoretical background, benefits, implementation, student perceptions and challenges of peer assessment. The next section will discuss these themes.

Peer assessment (PA) defined as the process by which the members of a group judge the extent to which their group members have exhibited specific traits, behaviours or achievements. ${ }^{24}$
PA is also defined as a process by which to consider the quality of a peer's performance, judge the extent to which it reflects goals or outcomes, and make suggestions for revision. ${ }^{25} \mathrm{PA}$ involves learners of the same academic level in the process of determining the quality, worth, or level of success of the outcomes of learning. ${ }^{26,27}$ It involves individuals who have attained the same general level of training or expertise, exercise no formal authority over each other and share the same hierarchic status in the institution. ${ }^{28,29}$ Mowl defined PA as a form of assessment that aims both to improve the quality of learning and to empower students. ${ }^{30}$

According to Davey and Foley, PA was introduced as a method of judgment in the $1770 \mathrm{~s},{ }^{31,32}$ while Stern argued that PA emerged in the 1920s, as a method of identifying leaders. Subsequently, it was utilised by public service organisations under pressure to improve their performance. ${ }^{33} \mathrm{PA}$ was first used in the medical setting in the 1950s as part of the comprehensive assessment of performance rather than to assess specific professional behaviours. ${ }^{34}$

In 1998, Topping determined the nature, quality, and extent of the PA literature. He identified a typology for PA, explored its theoretical underpinnings, clarified the mechanisms through which PA was effective, and gave recommendations for future PA research. ${ }^{27}$

PA aims to support the active engagement of learners in the assessment process to better achieve learning outcomes through the integration of learning and assessment. ${ }^{35-37}$

Student involvement in PA and peer marking leads to significant improvement in students' performance, supports students' learning and promotes the development of evaluation skills ${ }^{20,38}$ and encourages reflection. ${ }^{39}$

The theoretical Background of PA is connected collaborative learning and PA to the constructivism theory of learning; through collaborative learning experiences in PA, students construct their knowledge, develop critical thinking and problem-solving skills, improve their abilities to adapt to changes in their work environment and gain control over their learning. ${ }^{40}$

Social constructivism promotes the use of discussion and interaction between learners to develop the construction of knowledge. The Piaget model of cognitive conflict supports collaborative learning through learners' interactions, and Vygotsky's concept of scaffolded learning promotes communication as an implicit component of learning $;{ }^{27}$ both concepts are embedded in PA.

Students' involvement in PA ranges from written feedback through grades to group activities that allow students to discuss and build a learning product. PA requires learners to interact and communicate on certain levels. ${ }^{27,41}$

Constructivist activities require students to critically evaluate the information presented to them and allow them to interpret information for their learning 
purposes. ${ }^{42}$ These activities fit well with PA, as the process improves students' critical thinking and problem-solving abilities. . $^{17,26,43,44}$

Constructivist learning activities, including PA, have been shown to improve critical thinking and communication skills. ${ }^{45}$ The interaction among the students improved their lifelong learning skills; providing feedback was also a crucial element of independent learning that provided valuable learning opportunities. ${ }^{45}$

PA provides opportunities for students to reflect on their knowledge and skills. ${ }^{41,45,46}$ Activities that promote reflection by students are also key parts of the constructivist theory. Reflection provides students with an important opportunity to develop their skills as lifelong learners. ${ }^{45}$

PA improves student knowledge, ${ }^{47}$ it motivates students to succeed, improve academically, and perform better than other students on tests. ${ }^{48} \mathrm{~A}$ controlled trial study performed by McDonald and Boud revealed that students who participated in peer and self-assessment could achieve higher scores on future summative assessments. ${ }^{49}$ This finding was also noted in another study, but the authors insisted that students who actively engage in PA produce better-structured and betterorganised written assignments. ${ }^{50}$ The mutual review process of PA has a positive impact on student learning. ${ }^{51}$

PA allows students to evaluate themselves, comment on each other's work and develop more detailed knowledge, ${ }^{52}$ it permits students to become more aware of their strengths and weaknesses and encourages critical thinking skills. ${ }^{46}$ PA encourages students' problem-solving skills through observation of other students' abilities and analysis of the feedback provided to and given by peers. ${ }^{45,53}$

In addition, PA empowers students to control their learning. ${ }^{54}$ Students' involvement in the assessment process shifts the traditional teacher-centred practice into a more collaborative activity. Students' input through the PA process gives them some control over their learning and empowers them to take ownership of their education. ${ }^{40,44}$ In addition, shifting to collaborative learning and student-centred learning provides a stronger connection to the content compared to teacher-centred practice. ${ }^{55,56}$ Van Den Berg suggested that formative and summative self- and peer-assessments have many potential benefits for learning. ${ }^{57}$ Furthermore, Laverick proposed that PA can assist students in identifying which learning, teaching and assessment strategies work best for them. These skills are considered valuable because they differentiate expert learners from novices. ${ }^{58}$

PA stimulates higher-order thinking skills, encourages a deep learning approach, contributes to selfassessment by providing insight into student performance and increases students' confidence. ${ }^{59} \mathrm{PA}$ allows for immediate feedback from one or more individuals, thus providing an opportunity for students to gain a deeper understanding of content; ${ }^{17,56}$ metacognitive skills such as problem-solving and critical thinking are also enhanced through PA activities. ${ }^{17,20}$

Additionally, PA is associated with improvements in work habits and interpersonal skills ${ }^{60}$ and improves adherence to clinical practice guidelines. ${ }^{61}$ Participation in PA leads to improvements in the application of the learned material in professional settings. ${ }^{40}$

For faculty members, PA is considered a cost and time effective evaluation because it reduces the marking workload of faculty members. ${ }^{39,62}$ Likewise, PA permits faculty members to assess students less but better, ${ }^{59}$ and it maximises the effective utilisation of limited class time for both faculty members and students. ${ }^{63}$ Thus, Topping concludes that PA offers advantages to both the faculty member and the student. ${ }^{64}$

However, some literature has established that there is a lack of experimental studies on PA, but multiple literatures have determined that $\mathrm{PA}$ is an assessment method that fosters the achievement of learning outcomes, enriches the learning process and helps to develop metacognitive awareness. ${ }^{65,66}$ In addition, Liu and Lee reported that the continuous practice of PA would improve assessment and critical thinking skills. ${ }^{67}$

PA can be implemented as a summative or formative assessment. ${ }^{17,18}$ However, PA is used as a type of formative assessment rather than as a summative assessment, as students reject PA as a summative exercise. ${ }^{68}$ Internal alignment of the intended learning outcomes of teaching content and assessment tasks are required for successful implementation of PA. However, the involvement of all participants (students and faculty members) in discussions about PA (to maximise understanding of PA) and students' support during the process are important for proper execution of PA ${ }^{69}$

Consequently, for successful implementation of PA, Finn and Garner ${ }^{34}$ recommend the development of clear assessment criteria; organisation of the context that includes the type of assessment (summative or formative), due dates and other details; the proper timing of implementation; and providing students with the opportunity to reflect on their performance.

In particular, $\mathrm{Li}$ et al. stress the important roles of both assessors and assessees in the effective implementation of $\mathrm{PA},{ }^{70}$ and evaluation rubrics must be used to evaluate educational activities to ensure consistent feedback between students. ${ }^{71}$ Nevertheless, supporting the student throughout the PA process is important for proper implementation and proper alignment of the assessment and intended learning outcomes with the contexts that students may work in after graduation. ${ }^{69}$

\section{Discussion}

PA is a common method of evaluation ${ }^{72}$ and, students had a positive perception of it generally. ${ }^{46,73,74}$ Casey et al. noted that students enjoyed the process of PA and that it facilitates and enhances their learning and 
supports the self-regulation of learning ${ }^{26}$ Furthermore, students reported that they found the PA process helpful and beneficial. ${ }^{26}$ Collimore and Joordens recently stressed that students tend to have a positive attitude towards the implementation of PA in their courses. ${ }^{75}$ Mulder et al. explained that students show high satisfaction levels with the PA process, and they believe that it has a positive impact on their learning. ${ }^{76}$ According to Kaufman and Schunn, students' perceptions of peer feedback depend on the degree to which they think that the received feedback is unbiased, ${ }^{77}$ and, as suggested by Strijbos et al., feedback from a competent person is perceived to be more credible, satisfactory, agreeable, and useful. ${ }^{78}$

However, Gonzalez and Ignacio Godino-Llorente found that students recognised the usefulness of acting as peer assessors and showed higher confidence in instructor assessment than in PA, but they believed that the self-assessment that occurs during PA helped them more than the PA itself. ${ }^{79}$ On the other hand, students believe PA is unfair, and they consider their peers unqualified to review and assess their work. However, these beliefs will decline significantly after students' experience PA ${ }^{77}$ and Van Zundert et al. stressed that the practice of PA improves students' performances and positively affects their attitudes toward its practice. ${ }^{47}$ Nevertheless, Wheater et. al., stated that the practice of PA is a challenge for students and educators, yet it is useful, efficient and beneficial. ${ }^{39}$

PA can be a useful teaching and assessment method, but it is accompanied with challenges. It is not reliable, especially when completed by undergraduate students. ${ }^{17}$ Therefore, concerns about PA's reliability and validity were raised in the literature; reliability is the agreement between peers' grading, and validity is the agreement between PA and the instructor's assessment. ${ }^{72}$ Vickerman noted that students do not want to be perceived as rewarding themselves or their peers too easily. ${ }^{59}$ Thus, they will hold themselves and their peers to high standards. Studies show that students' grading is similar to instructors' grading and sometimes lower than that of instructors, but there is no significant difference. There is no apparent difference in validity even between novice and advanced students, but higher validity was noted when well-understood criteria were used. ${ }^{20}$ Recently, Strang found that there are no significant differences in ratings, and students' ratings were consistent with those of their teachers. ${ }^{80}$

On the other hand, Kennedy and Shih stressed that PA is time-consuming, adds to the workload of faculty members, and is challengeable; they concluded that the value of the practice is too limited. ${ }^{52,81}$ However, Vickerman and Basheti et al. concluded that PA maximises the effective utilisation of limited class time for faculty and students and permits teachers to assess students better..$^{59,63}$

While students' anxiety at the beginning of the PA process is common, this discomfort is reduced over time.
${ }^{46}$ In general, students are more comfortable receiving feedback from peers than providing feedback. ${ }^{82}$ Students with no experience of PA found it more difficult and require more support if they are to adopt it. ${ }^{37}$

To overcome these drawbacks, the authors recommended double marking by faculty members, multiple peer assessors, and clear grading criteria ${ }^{59}$ to reduce bias and improve PA's validity. ${ }^{15,34,62,83}$ In addition, students must feel that the environment is comfortable, safe and supportive. ${ }^{84}$ Anonymity is recommended in the PA process to ensure a safe environment, as it promotes students' comfort in providing and/or receiving peer feedback. ${ }^{63,82}$ Welsh recommended that PA used in formative assessments and that written feedback be provided, as students found comments to be more helpful than grades. ${ }^{46}$ Additionally, Strang emphasised the importance of training workshops to improve understanding of the PA process. ${ }^{80}$ Randomisation can help in PA, but it does not guarantee that immature students will conduct fair PA. ${ }^{80}$ PA is a useful formative assessment tool and can be good or bad depending upon how it is conducted. ${ }^{86}$

\section{Conclusion}

In reviewing the literature pertaining to peer assessment, its implementation, students' perceptions of it, and its strengths and limitations, the findings of published literature have been considered and appraised. There was consensus throughout the literature that peer assessment is both valuable and enjoyable for students. It is clear that the mutual process of peer assessment has a positive impact on student learning; it allows students to examine themselves, comment on each other's work and develop more detailed knowledge. Peer assessment motivates students to achieve better learning outcomes, promotes self-awareness and increases students' confidence. Peer assessment improves clinical performance, as student involvement in the assessment process promotes the development of critical thinking and problem-solving skills. Moreover, it will encourage self-assessment and reflective practice.

In general, PA is perceived positively among students, but the literature raises concerns about its reliability and validity. Similar to all assessment methods, peer assessment has advantages and drawbacks. However, multiple authors have endorsed recommendations to reduce its drawbacks and maximise its advantages. Consequently, special consideration is required regarding proper implementation, such as clear grading criteria and the formative nature of PA. Nevertheless, supporting the student throughout the PA process is important for proper implementation.

\section{Recommendation}

PA is useful and efficient for students and faculty members, but there are some recommendations: 
a. The practice of PA remains a challenge, and specific considerations are required for proper implementation.

b. PA requires careful planning to ensure alignment between the intended purpose and the practicalities of the assessment tools and processes.

c. For proper implementation of PA, a change management plan should be utilized because resistance from students, peers, and supervisors is expected.

d. More research is needed to support the validity, reliability, and impact of PA.

\section{References}

1. Schuwirth LW, van der Vleuten CP. General overview of the theories used in assessment: AMEE Guide No. 57. Medical teacher. 2011;33(10):783-97.

2. Brown G, Bull J, Pendlebury M. Peer and selfassessment. Assessing student learning in higher education London: Routledge. 1997:170-84.

3. Bloxham S, Boyd P. Developing Effective Assessment In Higher Education: A Practical Guide: A Practical Guide: McGraw-Hill Education (UK); 2007.

4. Brown S, Knight P. Assessing learners in higher education: Psychology Press; 1994.

5. Norcini J, Anderson B, Bollela V, Burch V, Costa MJ, Duvivier R, et al. Criteria for good assessment: Consensus statement and recommendations from the Ottawa 2010 Conference. Medical teacher. 2011;33(3):206-14.

6. Norcini J, Burch V. Workplace-based assessment as an educational tool: AMEE Guide No. 31. Medical teacher. 2007;29(9-10):855-71.

7. Cox M, Irby DM, Epstein RM. Assessment in medical education. New England Journal of Medicine. 2007;356(4):387-96.

8. Snyder BR. The Hidden Curriculum: Cambridge, Mass.,Mit Press; 1970.

9. Gibbs G. How assessment frames student learning. In: Bryan C, Clegg K, editors. Innovative assessment in higher education: Routledge;2006.

10. Cox K, Imrie BW, Miller A. Student assessment in higher education: a handbook for assessing performance: Routledge; 2014.

11. Cilliers FJ, Schuwirth LW, Adendorff HJ, Herman N, Van der Vleuten CP. The mechanism of impact of summative assessment on medical students' learning. Advances in health sciences education. 2010;15(5):695715.

12. Weurlander M, Söderberg M, Scheja M, Hult H, Wernerson A. Exploring formative assessment as a tool for learning: students' experiences of different methods of formative assessment. Assessment \& Evaluation in Higher Education. 2012;37(6):747-60.

13. Rust $\mathrm{C}$. The impact of assessment on student learning how can the research literature practically help to inform the development of departmental assessment strategies and learner-centred assessment practices? Active Learning in Higher Education. 2002;3(2):145-58.

14. Broekkamp H, Van Hout-Wolters BH. Students' adaptation of study strategies when preparing for classroom tests. Educational Psychology Review. 2007;19(4):401-28.

15. Black P, Wiliam D. Assessment and classroom learning. Assessment in education. 1998;5(1):7-74.
16. Crooks T. Assessment for learning in the accountability era: New Zealand. Studies in Educational Evaluation. 2011;37(1):71-7.

17. Gielen S, Dochy F, Onghena P. An inventory of peer assessment diversity. Assessment \& Evaluation in Higher Education. 2011;36(2):137-55.

18. Green SK, Johnson RL. Assessment is essential: McGraw-Hill Higher Education; 2010.

19. Carrillo-de-la-Peña MT, Bailles E, Caseras X, Martínez À, Ortet G, Pérez J. Formative assessment and academic achievement in pre-graduate students of health sciences. Advances in health sciences education. 2009;14(1):61-7.

20. Falchikov N. Improving assessment through student involvement: Practical solutions for aiding learning in higher and further education: Routledge; 2013.

21. Norcini J, \& Ben-David, M. Concept in Assessment. In: Dent J, Harden RM, editors. A practical guide for medical teachers: Elsevier Health Sciences;2013.

22. Al Kadri HM, Al-Moamary MS, Elzubair M, Magzoub ME, AlMutairi A, Roberts C, et al. Exploring factors affecting undergraduate medical students' study strategies in the clinical years: a qualitative study. Advances in health sciences education. 2011;16(5):553-67.

23. Swanwick T. Understanding medical education: Evidence, theory and practice: John Wiley \& Sons;2011.

24. Kane JS, Lawler EE. Methods of peer assessment. Psychological bulletin. 1978;85(3):555.

25. Topping K, editor. Peers as a source of formative and summative assessment. Los Angeles: Sage;2013.

26. Casey D, Burke E, Houghton C, Mee L, Smith R, Van Der Putten D, et al. Use of peer assessment as a student engagement strategy in nurse education. Nursing $\&$ health sciences. 2011;13(4):514-20.

27. Topping K. Peer assessment between students in colleges and universities. Review of educational Research. 1998;68(3):249-76.

28. Norcini JJ. Peer assessment of competence. Medical education. 2003;37(6):539-43.

29. Arnold L, Shue CK, Kritt B, Ginsburg S, Stern DT. Medical students' views on peer assessment of professionalism. Journal of general internal medicine. 2005;20(9):819-24.

30. Mowl G. Innovative student assessment. Retrieved February. 1996;8:2010.

31. Davey K. Student self-assessment: Results from a research study in a level IV elective course in an accredited bachelor of chemical engineering. Education for Chemical Engineers. 2015;10:20-32.

32. Foley S. Student views of peer assessment at the International School of Lausanne. Journal of Research in International Education. 2013;12(3):201-13.

33. Stern DT, Stern D. A framework for measuring professionalism. Measuring medical professionalism. 2006:3-14.

34. Finn GM, Garner J. Twelve tips for implementing a successful peer assessment. Medical teacher. 2011;33(6):443-6.

35. Asikainen H, Virtanen V, Postareff L, Heino P. The validity and students' experiences of peer assessment in a large introductory class of gene technology. Studies in Educational Evaluation. 2014;43:197-205.

36. Davey K. Student peer assessment: Research findings from a case study in a master of chemical engineering coursework-program. Education for Chemical Engineers. 2011;6(4):e122-e31.

37. McGarr O, Clifford AM. 'Just enough to make you take it seriously': exploring students' attitudes towards peer assessment. Higher education. 2013;65(6):677-93. 
38. Bryer J. Peer tutoring program for academic success of returning nursing students. The Journal of the New York State Nurses' Association. 2011;43(1):20-2.

39. Wheater CP, Langan AM, Dunleavy PJ. Students assessing student: case studies on peer assessment. Planet. 2005(15):13-5.

40. Hodges HF. Preparing new nurses with complexity science and problem-based learning. Journal of Nursing Education. 2011;50(1):7.

41. Yurdabakan I. The investigation of peer assessment in primary school cooperative learning groups with respect to gender. Education 3-13. 2011;39(2):153-69.

42. Powell KC, Kalina CJ. Cognitive and social constructivism: Developing tools for an effective classroom. Education. 2009;130(2):241.

43. Blaik-Hourani R. Constructivism and revitalizing social studies. The History Teacher. 2011:227-49.

44. Schunk DH. Learning theories : an educational perspective. Boston: Pearson;2012.

45. Luxton-Reilly A, Denny P. Constructive evaluation: a pedagogy of student-contributed assessment. Computer Science Education. 2010;20(2):145-67.

46. Welsh MM. Engaging with peer assessment in postregistration nurse education. Nurse education in practice. 2007;7(2):75-81.

47. Van Zundert M, Sluijsmans D, Van Merriënboer J. Effective peer assessment processes: Research findings and future directions. Learning and Instruction. 2010;20(4):270-9.

48. Eldredge JD, Bear DG, Wayne SJ, Perea PP. Student peer assessment in evidence-based medicine (EBM) searching skills training: an experiment. Journal of the Medical Library Association: JMLA. 2013;101(4):244.

49. McDonald B, Boud D. The impact of self-assessment on achievement: the effects of self-assessment training on performance in external examinations. Assessment in Education: Principles, Policy \& Practice. 2003;10(2):20920.

50. Van den Berg I, Admiraal W, Pilot A. Design principles and outcomes of peer assessment in higher education. Studies in Higher Education. 2006;31(03):341-56.

51. Harris JR. Peer assessment in large undergraduate classes: an evaluation of a procedure for marking laboratory reports and a review of related practices. Advances in physiology education. 2011;35(2):178-87.

52. Shih R-C. Can Web 2.0 technology assist college students in learning English writing? Integrating Facebook and peer assessment with blended learning. Australasian Journal of Educational Technology. 2011;27(5):829-45.

53. Marty MC, Henning JM, Willse JT. Accuracy and reliability of peer assessment of athletic training psychomotor laboratory skills. Journal of athletic training. 2010;45(6):609.

54. Wasson B, Vold V. Leveraging new media skills for peer feedback. The Internet and Higher Education. 2011;15(4):255-64.

55. Rolloff M. A constructivist model for teaching evidencebased practice. Nursing education perspectives. 2010;31(5):290-3.

56. Rush S, Firth T, Burke L, Marks-Maran D. Implementation and evaluation of peer assessment of clinical skills for first year student nurses. Nurse education in practice. 2012;12(4):219-26.

57. van den Berg I, Admiraal W, Pilot A. Peer assessment in university teaching: evaluating seven course designs. Assessment \& Evaluation in Higher Education. 2006;31(1):19-36.
58. Laverick DM. Motivation, metacognition, mentors, and money: Ingredients that support teaching expertise. Early Childhood Education Journal. 2007;34(4):247-9.

59. Vickerman P. Student perspectives on formative peer assessment: an attempt to deepen learning? Assessment \& Evaluation in Higher Education. 2009;34(2):221-30.

60. Spandorfer J, Puklus T, Rose V, Vahedi M, Collins L, Giordano C, et al. Peer assessment among first year medical students in anatomy. Anatomical sciences education. 2014;7(2):144-52.

61. Maas MJ, van der Wees PJ, Braam C, Koetsenruijter J, Heerkens YF, van der Vleuten CP, et al. An innovative peer assessment approach to enhance guideline adherence in physical therapy: single-masked, cluster-randomized controlled trial. Physical therapy. 2015;95(4):600-12.

62. Gibson PA, Dunning PT. Creating quality online course design through a peer-reviewed assessment. Journal of Public Affairs Education. 2012:209-28.

63. Basheti IA, Ryan G, Woulfe J, Bartimote-Aufflick K. Anonymous peer assessment of medication management reviews. American journal of pharmaceutical education. 2010;74(5).

64. Topping KJ. Peer assessment. Theory into practice. 2009;48(1):20-7.

65. van Zundert MJ, Sluijsmans DM, Könings KD, van Merriënboer JJ. The differential effects of task complexity on domain-specific and peer assessment skills. Educational Psychology. 2012;32(1):127-45.

66. Çevik YD, Haşlaman T, Çelik S. The effect of peer assessment on problem solving skills of prospective teachers supported by online learning activities. Studies in Educational Evaluation. 2015;44:23-35.

67. Liu EZ-F, Lee C-Y. Using Peer Feedback to Improve Learning via Online Peer Assessment. Turkish Online Journal of Educational Technology-TOJET. 2013;12(1):187-99.

68. Patton C. 'Some kind of weird, evil experiment': student perceptions of peer assessment. Assessment \& Evaluation in Higher Education. 2012;37(6):719-31.

69. Thomas G, Martin D, Pleasants K. Using self-and peerassessment to enhance students' future-learning in higher education. Journal of University Teaching \& Learning Practice. 2011;8(1):5.

70. Li L, Liu X, Zhou Y. Give and take: A re-analysis of assessor and assessee's roles in technology-facilitated peer assessment. British Journal of Educational Technology. 2012;43(3):376-84

71. Stevens DD, Levi AJ. Introduction to rubrics: An assessment tool to save grading time, convey effective feedback, and promote student learning: Stylus Publishing, LLC;2011.

72. Weaver D, Esposto A. Peer assessment as a method of improving student engagement. Assessment \& Evaluation in Higher Education. 2012;37(7):805-16.

73. Li L. How do students of diverse achievement levels benefit from peer assessment? International Journal for the Scholarship of Teaching and Learning. 2011;5(2):14.

74. Shiu AT, Chan CW, Lam P, Lee J, Kwong AN. Baccalaureate nursing students' perceptions of peer assessment of individual contributions to a group project: A case study. Nurse education today. 2012;32(3):214-8.

75. Collimore L-M, Paré DE, Joordens S. SWDYT: So What Do You Think? Canadian students' attitudes about peerScholar, an online peer-assessment tool. Learning Environments Research. 2015;18(1):33-45.

76. Mulder RA, Pearce JM, Baik C. Peer review in higher education: Student perceptions before and after 
participation. Active Learning in Higher Education. 2014:1469787414527391.

77. Kaufman JH, Schunn CD. Students' perceptions about peer assessment for writing: their origin and impact on revision work. Instructional Science. 2011;39(3):387-406.

78. Strijbos J-W, Narciss S, Dünnebier K. Peer feedback content and sender's competence level in academic writing revision tasks: Are they critical for feedback perceptions and efficiency? Learning and Instruction. 2010;20(4):291-303.

79. Gonzalez de Sande JC, Ignacio Godino-Llorente J. Peer Assessment and Self-assessment: Effective Learning Tools in Higher Education. International Journal of Engineering Education. 2014;30(3):711-21.

80. Strang KD. Effectiveness of Peer Assessment in a Professionalism Course Using an Online Workshop. Journal of Information Technology Education: Innovations in Practice. 2015;14:1-16.

81. Kennedy GJ, editor. Peer-assessment in group projects: is it worth it? Proceedings of the 7th Australasian conference on Computing education-Volume 42; 2005 : Australian Computer Society, Inc.

82. Wu K, Davison L, Sheehan AH. Pharmacy students' perceptions of and attitudes towards peer assessment within a drug literature evaluation course. American journal of pharmaceutical education. 2012;76(4).

83. Airasian PW, Russell MK. Classroom assessment: Concepts and applications. 2001.

84. Tillema H, Leenknecht M, Segers M. Assessing assessment quality: Criteria for quality assurance in design of (peer) assessment for learning-a review of research studies. Studies in Educational Evaluation. 2011;37(1):25-34.

85. Dannefer EF. Beyond assessment of learning toward assessment for learning: Educating tomorrow's physicians. Medical teacher. 2013;35(7):560-3.

86. Elshami W, Abdalla, ME, Diagnostic radiography students perceptions of formative peer assessment within a radiographic technique module. Radiography. 2017;23(1):9-13. 